\title{
Impact of Artificial Elements on Mountain Landscape Perception: An Eye-Tracking Study
}

\author{
Suling Guo ${ }^{1,2}$, Wei Sun ${ }^{1,2, *(\mathbb{D}, \text { Wen Chen }}{ }^{1,3}$, Jianxin Zhang ${ }^{4}$ and Peixue Liu ${ }^{4}$ \\ 1 Key Laboratory of Watershed Geographic Sciences, Nanjing Institute of Geography \& Limnology, Chinese \\ Academy of Sciences, East Beijing Road 73, Nanjing 210008, China; slguo@niglas.ac.cn (S.G.); \\ wchen@niglas.ac.cn (W.C.) \\ 2 University of Chinese Academy of Sciences, Yuquan Road 19A, Beijing 100049, China \\ 3 College of Resources and Environment, University of Chinese Academy of Sciences, Yuquan Road 19A, \\ Beijing 100049, China \\ 4 School of Geography and Ocean Science, Nanjing University, 163 Xianlin Street, Nanjing 210023, China; \\ bokaimiwu@nju.edu.cn (J.Z.); pixliu@nju.edu.cn (P.L.) \\ * Correspondence: wsun@niglas.ac.cn
}

Citation: Guo, S.; Sun, W.; Chen, W.; Zhang, J.; Liu, P. Impact of Artificial Elements on Mountain Landscape Perception: An Eye-Tracking Study. Land 2021, 10, 1102. https://doi.org/ 10.3390/land10101102

Academic Editors: Baojie He, Ayyoob Sharifi, Chi Feng, Jun Yang and César Parcero-Oubiña

Received: 25 August 2021

Accepted: 14 October 2021

Published: 17 October 202

Publisher's Note: MDPI stays neutral with regard to jurisdictional claims in published maps and institutional affiliations.

\begin{abstract}
The landscape is an essential resource for attracting tourists to a destination, but this resource has long been overused by tourism development. Tourists and scholars have begun noticing the interference of human structures in the natural environment and how this can change the meaning of a landscape. In this study, the impact of artificial elements on mountain landscapes was investigated by measuring the characteristics of visual perception and a landscape value assessment using eye-tracking analysis. Furthermore, this study includes socio-demographic features for testing whether they have an impact on landscape perception. The results show that human structures impact both visual perception and the perceived value of landscapes. Hotels and temples attract more visual attention than a purely natural landscape. Modern hotels appear to have a negative influence on mountain landscape valuation, while temples with unique culture have positive impacts. Socio-demographic groups differ significantly in how they observe landscape images and, to a degree, how they value the landscape therein. Our study should be of value to landscape planning and tourism policy making.
\end{abstract}

Keywords: landscape perception; artificial element; eye movement; socio-demography; tourism resource conservation

\section{Introduction}

A landscape can be defined as a space viewed or appreciated by a person or the scenery of one's daily life. The landscape is endowed with values by its inherent aesthetics, culture, or other merits that can be perceived by people's senses [1]. Continued research on landscapes has altered the way people think about it; a more current conception of the landscape is an environment produced by ongoing interaction between human and the surroundings around them [2-4]. Therefore, a landscape can be recognized by its two features: the landscape is formed by the interaction between human beings and the environment around them, and it is perceived or evaluated by people for its meaning within a place. The unique emotional or physical experience the landscape attracts tourists [5,6]. However, these important tourism resources are being consumed excessively in modern society, resulting in problems such as unsustainable utilization and environmental visual pollution. As one of the fastest-growing economic activities in China, tourism development alters the landscape by shaping its appearance and, therefore, the original meaning of a place. Modern structures or facilities interfering the landscape may alter people's perception and, in turn, their preference for tourism destinations, perhaps leading them to abandon it.

Perception is an intrinsic attribute of the landscape. Expressed in the form of space, the composition and layout of a landscape constitute what it affords; that is to say that 
landscape affordance can be received spontaneously by people's sensory organs [7]. Visual sense plays a vital role in landscape perception; studies have demonstrated that people apperceive about 80 percent of outsider information through their visual systems [8]. A large amount of research has been conducted and involves the visual aspects of landscapes, and they are mostly carried out under the psycho-physical paradigm that regards landscape perception as a result of a stimulus-response relationship between human beings and the surrounding environment [1,9-12]. Aesthetic value receives most of the attention in landscape visual studies. Different landscapes show a variety of aesthetic features, yet they share certain underlying concepts in common. An index system for assessing the aesthetic value of a landscape consists of common indicators such as harmony, diversity, and mystery; systems that are similar have been studied, established, and applied in research and projects [4,13-16]. Daniel and Boster (1976) initially came up with the Scenic Beauty Estimation (SBE) method to evaluate the visual quality of a forest landscape [13]. A Semantic Differential (SD) scale is another frequently used method for evaluating landscape visual quality [17]. Related research has been extended to the landscape studies of cities, rural areas, gardens, roads, and more [18-21]. Cultural value is another essential landscape attribute that people perceive. As the most distinct feature in a regional context, culture can be seen as a type of immaterial tourism resource, and its outcomes provide economic benefit $[22,23]$. Tourists always pursue the sense of place or special experience generated by a unique cultural environment [24-26]. Other related studies have focused on the intrinsic meaning of cultural landscapes or places, the utilization and protection of heritage, the value and management of rural or urban cultural landscapes, and the environmental concerns as a landscape or a place has changed [27-32].

As modernism has globally spread, a question has been raised regarding whether modern architecture truly fits into landscapes with inherent local natural and cultural values. A landscape visual impact would be brought forth if the landscape changed when some entities invaded or moved out, causing a general irritation of emotional or psychological harm to viewers [33-35]. Relevant studies have focused on the harmony of human facilities set in a natural environment, the authenticity of landscape reconstruction, and world heritage protection [36-42]. In recent years, obtrusive man-made facilities and buildings interfering in scenic spots have irritated tourists and earned the notoriety, similarly to a misplaced brushstroke in a painting. Landscape reconstruction and visual threshold can be analyzed via GIS or an evaluation scale questionnaire, and such tools are important for investigating a landscape's visual impact [43-45]. Many studies focus on how man made facilities such as roads, buildings, and renewable-energy farms affect the landscape's natural properties and cause visual pollution [46-49]. There are some studies conducted to discuss the impact of cultural elements on the natural landscape during tourism development $[31,50]$. Little research has been conducted on modern buildings or facilities installed at natural tourism destinations. Built facility expansion resulting from tourism or other economic activities is the main theme in the impact of artificial elements research, including both positive and negative impacts [51-53]. Visual impact is one of the most common factors that account for the unsustainable utilization of tourism resources, but researchers have long been neglecting it. This study tested the impact of artificial element intervention in natural tourism resources from a perception perspective. Our study tries to fill in these gaps in existing research.

According to environmental cognitive psychology, a landscape as a stimulus can be perceived simultaneously and spontaneously through two processes: a top-down mode and a bottom-up mode. Bottom-up is an 'outside-in' information process, i.e., a variety of information from the external environment stimulates people's feelings and causes them to reflect. The landscape component as external information refers to physical features such as artificial buildings or the entire cultural or natural appearance of a landscape. Topdown means an 'inside-out' target-tracking task driven by the conceptions or established knowledge obtained from previous experience [54-56]. The human component such as internal consciousness encompasses past experience, knowledge, and expectations 
shaped by an individual's or a group's socio-cultural context [57,58]. Demographics has been studied as a variable that partly explains the differences among several groups in landscape preference, tourism destination choice, and environmental behavior. Gender, age, education, income, ethnicity, and childhood background are the main characteristic descriptors in such studies [59-65]. Landscape is a discourse constructed from a method of perception that represents an identifiable socio-demographic group owing to a particular cultural mode or collective value [2]. Due to the fact that certain experiences, values, or attitudes shared by one group are different from the others, landscape perception varies between different groups and different levels of certain properties, including expertise and ethnicity [66-68]. Two types of landscape perception and evaluation approach are developed: an expert/design approach and a public perception-based approach [69]. The first focuses on knowledge about landscape attributes that is evaluated by several experts; the latter involves evaluations from public perspectives and is considered a more reliable measure [69-71]. Although the public participation method has been used in urban and tourism planning, a human's perception is still difficult to measure quantitatively, and often a more holistic and innovative method is needed [72,73].

The interaction between the physical landscape and personal knowledge is expressed through visual characteristics, landscape assessment, and attitude. Likewise, visual exploration can be explained as driven by two main factors: environmental stimuli and our own individual interests and intentions. Therefore, landscape value assessment results might be connected to the visual features demonstrated by physical eye movements [74-76]. As a psychological method, eye-tracking has been employed recently in landscape visual perception research. Visual behavior can be measured quantitatively and objectively through eye-tracking experiments, which entails, for example, a direct documentation of the location, duration, and order of the subjects' gazes; all of this can be obtained easily, clearly revealing the visual perceptual process $[77,78]$. Eye tracking has been applied in research on forest landscape [79], urban green space [73,80,81], landmark landscape [82], and rural landscape $[66,75,83]$ in recent years. Landscape characteristics such as format, color, and openness have been applied as main variables in landscape perception. Some studies focus on the socio-demographic or acoustic variables during the landscape viewing process and demonstrate that humanistic elements do have an impact on landscape visual behaviors $[73,79,84,85]$. The visual impact of humanistic attributes on the natural landscape is usually discussed in this research area, but a negative or positive value assessment is lacking. Some research focuses on the tourism advertising effect $[86,87]$ and tourism map cognition [88-90]. Little research has been constructed from the utilization of tourism landscapes $[84,91,92]$, and the impact of artificial elements on tourism landscapes is rarely studied. The key point of these studies is the difference in landscape visual attention or landscape attractiveness. The mechanism behind the difference in visual perception still requires future research.

A theory and literature review demonstrates that landscape perception has been studied for a long time, but most analysis is concerned mainly with the separate views of either landscape surface features or different groups of observers; analysis combining external and internal factors as an entire landscape perception system remains to be discussed in depth. We, therefore, found our research conception framework based on the environmental cognitive process (Figure 1). Traditional methods such as a questionnaire survey are generally used in studies of landscape perception. Eye tracking as a more objective method has been applied in landscape studies recently, but there is little research on the impact of artificial elements on tourism landscapes. Modern tourism has been developed along with globalization; the impact of this development on the landscape requires further research. This article quantifies visual perception and value assessments as artificial elements and external stimuli that interfere in a natural landscape. Demographically, we also investigated landscape perception variations between different groups. Finally, the applicability of the eye movement analysis method relative to landscape perception and assessment research is discussed. Our hypotheses are as follows: (1) artificial elements in a natural landscape 
cause differences in visual behavior, (2) artificial elements in a natural landscape cause differences in landscape value assessment, and (3) social demographics have an impact on landscape observation and evaluation.

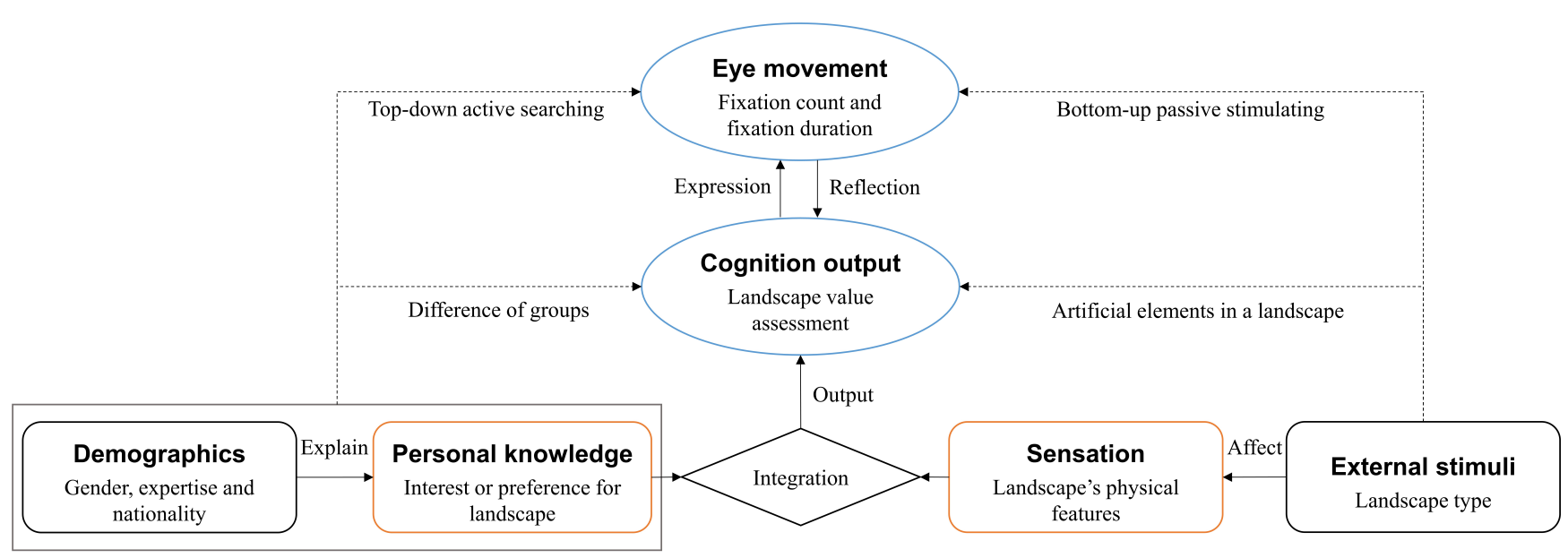

Figure 1. Conceptual framework of landscape perception.

\section{Data and Methodology}

\subsection{Case Selection}

As one of the most important resources for tourism, the mountain landscape has long been utilized for leisure purposes. Located in a densely populated area, because of their accessibility with a convenient transportation, the pleasant nature at a comfortable altitude (most of the mountains are below $2000 \mathrm{M}$ in height), and the rich culture of religion and literature, the the mountains of Eastern China were tourist destinations first and only underwent intensive tourism development in recent years [93-95]. It is precisely because of the unique natural and cultural values the mountains are endowed with that many of them are listed as either natural or cultural World Heritage Sites or both. Mount Tai, for example, was listed as a World Cultural and Natural Heritage Site by UNESCO in 1987 as it was "the object of an imperial cult [...], and the artistic masterpieces found there are in perfect harmony with the natural landscape" [96]. On such values, the mass tourism development of mountains in Eastern China began, along with China's reform and opening up, and went through rapid development from the late 20th century. Tourism development for mountains is experiencing intense conflicts between utilization and protection. These mountains are always popular scenic spots in holidays. For example, about 166,200 tourists visited Mount Tai in 2019 on the Labor Day holiday, and 5.68 million tourists in total visited over the entire year. Mount Huang has maintained over 3 million tourists per year since 2012, except for the years after the outbreak of the coronavirus pandemic. Unlike the old temples that were shaped in harmony with the landscape, large modern buildings and facilities are being created to accommodate a large number of tourists. Landscape protection gives way to maximizing economic benefit. The mountain landscape has been severely devastated, and people's perception and value assessment of it is changing [94,97]. Accurately assessing the impact of artificial elements on mountain landscape perception and evaluation will contribute to resolving the tourism paradox of protection and exploitation.

\subsection{Research Design}

\subsubsection{Experimental Design}

A two by three experimental design was applied in this study. The landscape type is the within-subject variable, and it has three levels: the natural landscape, the temple landscape, and the hotel landscape. The between-subject variables are gender, expertise, and nationality, each of which has two levels: male and female, expert and layman, 
and Chinese and foreigner, respectively. The dependent variables are landscape value assessment and eye movement characteristics.

\subsubsection{Photograph Stimuli}

Landscape photographs have been chosen as experiment stimuli in previous landscape studies and have proven to have the same effect with the real landscape [98-100]. In this study, three similar photos for each landscape type, nine in total, were selected from the official websites of tourism bureaus or scenic spot committees. The images posted on the official website were regarded as the distinctive landscapes in a scenic area. The official websites are always the first and most important info portal for tourists, so the images on official websites are viewed frequently by the masses and are familiar to them. The images on official websites are endowed with the representativeness of the real mountain landscape. With rich natural and cultural connotations, the mountain landscape has experienced a long period of tourism development history, such as those of Mount Tai and Mount Huang (Figure 2). A long shot or a medium shot view was applied when selecting the landscape photos.

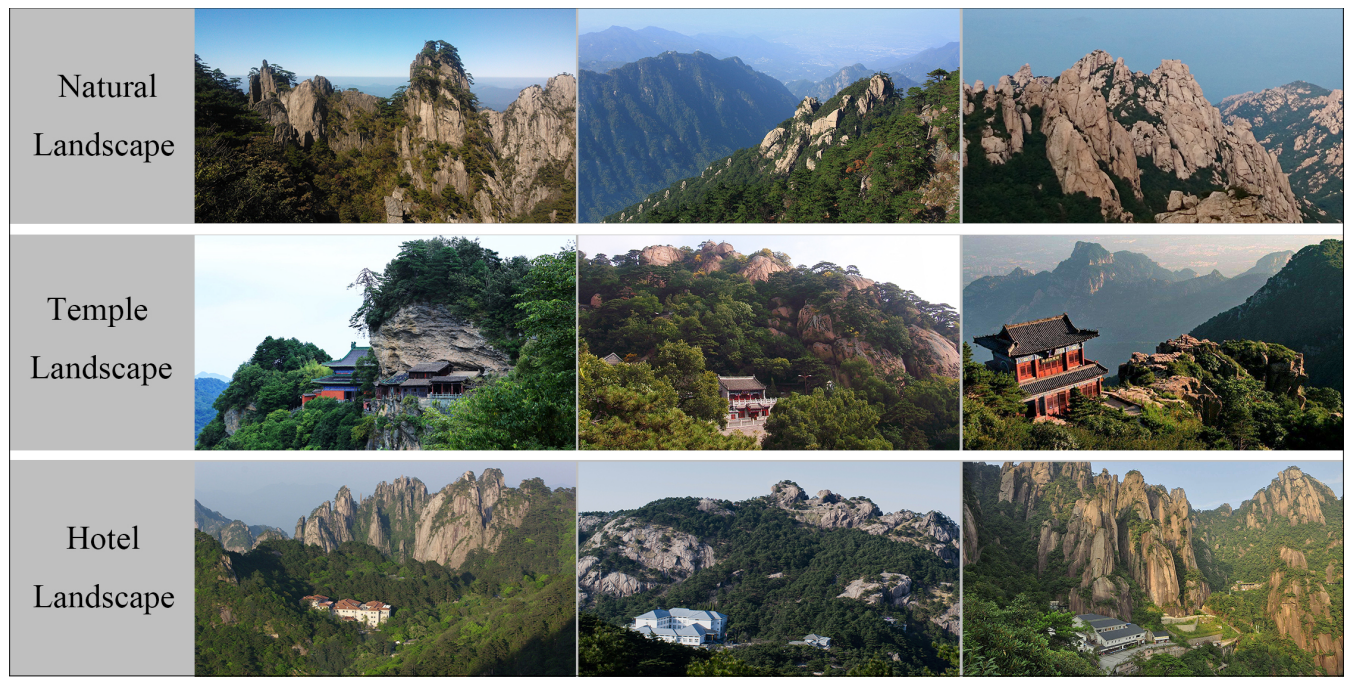

Figure 2. Landscape images. Images were selected from the official websites of tourism bureaus or scenic spot committees, including the Management Committee of Huangshan National Park (http:/ /hsgwh.huangshan.gov.cn/) (accessed on 26 February 2018), the Management Committee of Scenic Spots and Historic Sites of Taishan (http:/ / tsgw.taian.gov.cn/) (accessed on 26 February 2018), the Wudang Mountains Tourism Portal (http://ly.wudangshan.gov.cn/) (accessed on 26 February 2018), the Mount Laoshan tourism Portal (http:/ / www.qdlaoshan.cn/) (accessed on 26 February 2018), and the Committee of Mount Jiuhua (http:/ / www.jiuhuashan.gov.cn/) (accessed on 26 February 2018).

\subsubsection{Mountain Landscape Value Assessment Scale}

The mountain landscape was evaluated from the perspective of tourists' perceptions. The assessment index system has been well studied. Four indicators of coherence, complexity, legibility, and mystery were chosen in the environmental preference evaluation in Kaplan's research [101]. Tveit, Ode, and Fry presented a framework for analyzing landscape visual characteristics based on nine key visual concepts, namely stewardship, coherence, disturbance, historicity, visual scale, imageability, complexity, naturalness, and ephemera [35,40,102]. Aesthetic values and cultural values are the major components used in mountain landscape evaluation; visitors are attracted to these mountains principally because of these two values in Eastern China $[93,94]$. In this research, aesthetic and cultural values were emphasized in the mountain landscape value assessment. Five indices for both aesthetics and culture were itemized based on the landscape assessment system of Kaplan, Tveit, Ode, and Fry. Charm, ecology, peace, diversity, and harmony were likewise 
selected for the aesthetic value assessment, and peculiarity, typicality, cultural connotation, mystery, and protection value were selected for the cultural value assessment (Table 1). Furthermore, the Outstanding Universal Value (OUV) assessment system set by UNESCO as the main tool in World Heritage Site selection, which includes six cultural and four natural criteria emphasizing uniqueness, historicity, aesthetic, geomorphology, ecology, etc., was also referred to in our mountain landscape value assessment system [103]. The questionnaire consisted of two parts: a five-point Likert scale of value assessment and a demographic information survey.

Table 1. Mountain landscape value assessment scale (Ath means aesthetic value and Cul means cultural value).

\begin{tabular}{ccc}
\hline Assessment Content & Index & Index Description \\
\hline Aesthetic value & Ath1 & This landscape has graceful charm. \\
Aesthetic value & Ath2 & This landscape is ecologically vibrant. \\
Aesthetic value & Ath3 & This This landscape makes me feel peaceful. \\
Aesthetic value & Ath4 & This landscape contains much diversity. \\
Aesthetic value & Ath5 & This landscape is harmonious. \\
Cultural value & Cul1 & This landscape reflects the peculiar characteristics of a mountain landscape. \\
Cultural value & Cul2 & This landscape represents the characteristics of mountains in China. \\
Cultural value & Cul3 & This landscape has profound cultural connotations. \\
Cultural value & Cul4 & This landscape is full of mystery. \\
Cultural value & Cul5 & This landscape contains significant value and ought to be protected.
\end{tabular}

\subsection{Subjects and Data Collection}

\subsubsection{Subjects}

A total of 106 students with either normal or corrected vision from Nanjing University (NJU) were invited to participate in the experiment by using informative flyers and posters distributed throughout NJU. College students are considered to have a certain level of knowledge in terms of thinking and acting independently. They tend to pay more attention to tourism information. Thus, they can perceive and evaluate the tourism landscape more quickly and accurately. After manually scrutinizing and excluding abnormal values (extreme and zero values), data of 96 subjects were filtered and assessed as effective for analysis in this study. Of the 96 subjects, 51 percent were males and 49 percent were females; students with landscape-or tourism-related expertise (experts) accounted for 37.5 percent, and laymen accounted for 62.5 percent. Chinese subjects accounted for 78.1 percent, and foreigners accounted for 21.9 percent. The foreign participants' countries of origin included Germany, Pakistan, Indonesia, South Korea, Russia, Ukraine, and Vietnam.

\subsubsection{Data Collection}

During the experiment, an SMI MOBILE eye tracker was used with a laptop (1600* 900 screen resolution) to track the subjects' eye movements, and an iPad was used for the landscape value assessment questionnaire survey. At first, the subjects were asked to view the photos on the laptop screen in a random order. After finishing one photo, the subjects would press the left arrow to view the next one. Subject-controlled viewing time for each photo prevented insufficient viewing time or observational data that did not reveal real landscape preference and eye movement characteristics. After the eye-tracking experiment, the subjects were asked to complete a landscape value assessment questionnaire about the landscapes they had just viewed on the laptop. Each experiment of the subjects lasted about three minutes.

\subsection{Data Analysis}

\subsubsection{General Analysis of ETM}

BeGaze 3.7, the software package provided with the SMI eye-tracker, was used to export the data of eye tracking metrics (ETM) in well-structured Excel files. Fixation count (FC) and fixation duration (FD) were selected as the eye movement indicators based on 
which subjects' perception behavior would be analyzed $[87,104]$. Fixation count (FC) is the number of fixations measured in counts (c). A higher FC indicates that the participants processed more but not necessarily useful information during the viewing time. Fixation duration (FD) is the total duration time of all fixations for an image, measured in seconds (s). The longer the FD, the more interested the participants were [90].

Since each landscape type included three similar landscape images, the subjects' FC and FD for each landscape type were calculated by averaging the values of the three similar landscape images. Multiplying 96 subjects by three landscape types and by two eye movement indicators yielded data containing 576 eye movement records in total. Aesthetic and cultural landscape values were integrated by averaging their five index scores for the three similar landscape pictures. Similarly, the data of the 576 records of landscape value assessment indicators were usually distributed. A log transformation was applied to convert eye movement data into the normal distribution for later analysis.

\subsubsection{Creating the Eye-Tracking Maps}

A heat map can be created in BeGaze 3.7 directly. The heat map is projected onto the original image to highlight the observed areas. On the heat map, red means a high amount of observations, green means a lower amount, and no color means almost no observation. Our research obtained nine heat maps by positioning fixation points and overlaying viewing time on landscape images (Figure 3). A scan path map can be created by orderly connecting lines between the fixation points in BeGaze 3.7. The scan path map shows the attention process. Subjects in a landscape always notice prominent elements. We, therefore, can obtain the attention sequence by analyzing the scan path. By capturing the scan path characteristics at the 0.1 th second and the 0.5 th second of the viewing process, we obtained six scan path maps (Figure 4).

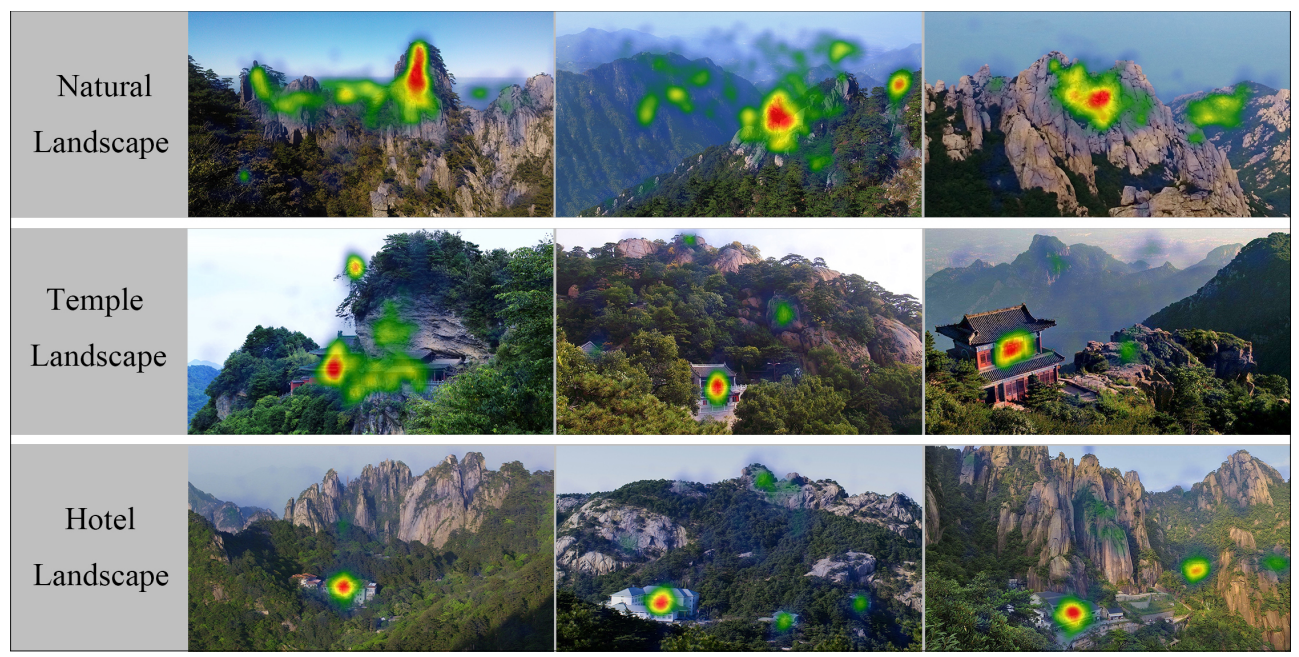

Figure 3. Heat maps of landscape images. 
a

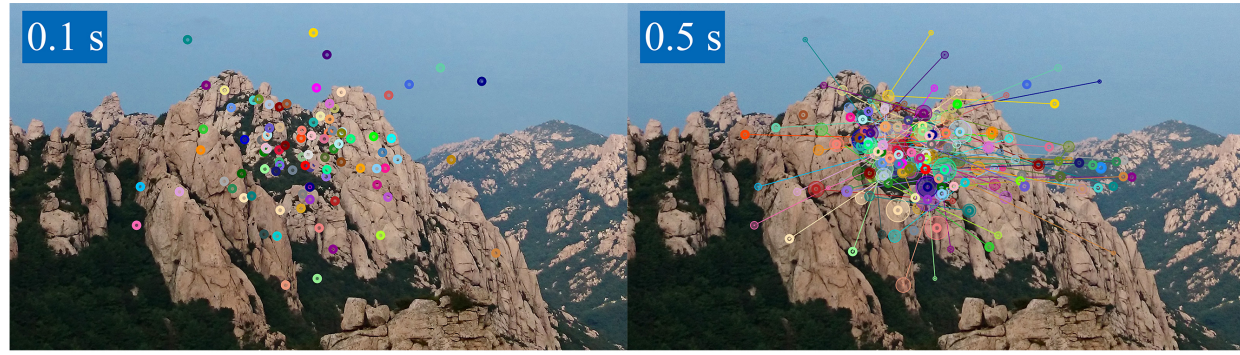

b

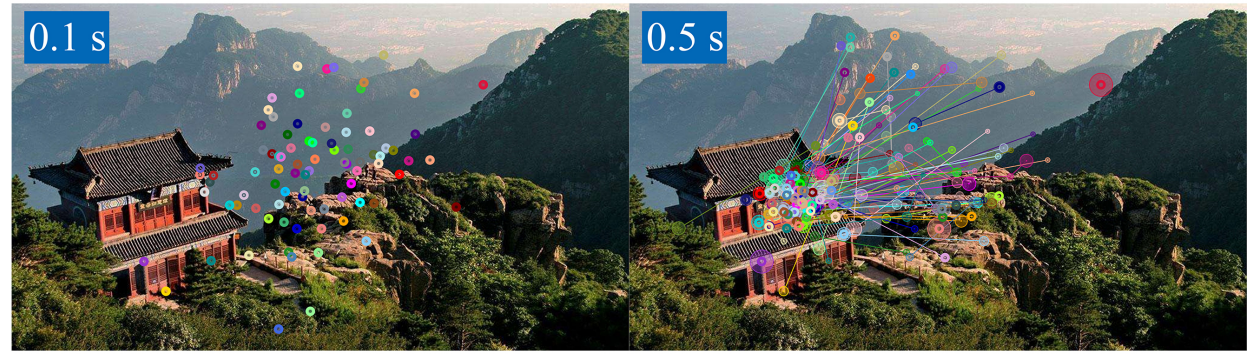

C

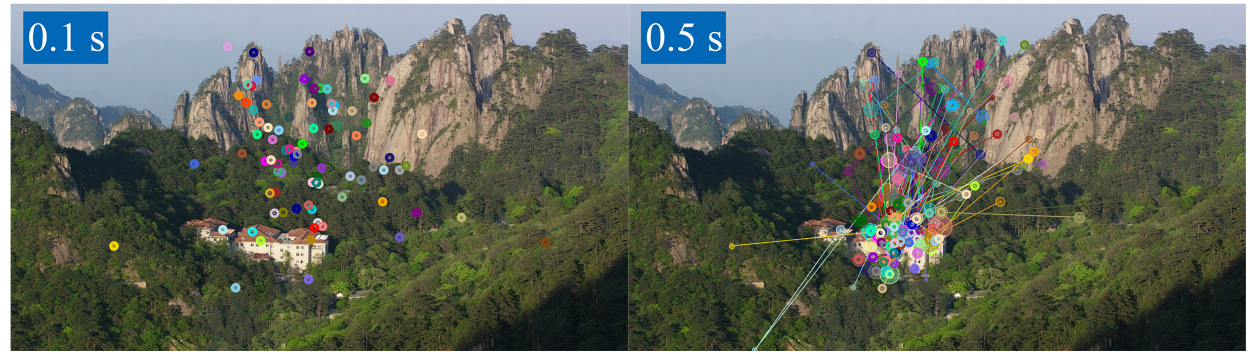

Figure 4. Scan path maps of three types of landscapes at $0.1 \mathrm{~s}$ and $0.5 \mathrm{~s}$ : (a) the natural landscape, (b) the temple landscape, and (c) the hotel landscape.

\subsubsection{Perception Difference of Three Landscapes and Demographics Analysis}

The classical difference analysis method was applied in this research. One-way repeated measures ANOVA was conducted to test the difference of visual behavior and landscape value assessment among natural, temple, and hotel landscapes. A least significant difference pairwise comparison method was used to further discuss each difference between the three landscapes. Two variables, landscape type and demographics, were tested by using two-way repeated measures ANOVA to test the demographic differences. Furthermore, the differences in demographic features were also obtained from the tests of the between-subjects effect.

\section{Results}

\subsection{Eye-Tracking Maps of Landscape Images}

Heat maps can be created by positioning fixation points and overlaying viewing time on landscape images. By visualizing all the fixation points and the total fixation duration from the 96 subjects, nine heat maps of the landscape images were obtained (Figure 3). The heat maps analysis indicates that natural landscapes encompassed a wider visual scope. For natural landscapes, visual attention not only concentrated on the center of the image but also scattered around the center. Visual attention on the temple landscape and the hotel landscape focused mainly on the artificial elements in the image and was constrained within a relatively smaller area than the natural landscape. The visual difference between the natural landscape and the landscapes with an artificial element is clearly presented in heat maps. Therefore, hypothesis one was demonstrated to be true.

Nearly all the subjects' visual focus was fixed on the image center for all landscape types at the 0.1 th second of the experiment. At the 0.5 th second, the subjects' second fixation point appeared; viewing paths were drawn by connecting these two points with a line (Figure 4). In the temple and hotel landscapes, nearly all the subjects' second fixation points were located on the artificial elements in the temple and hotel landscapes. This 
differs from the natural landscape. In the natural landscape, the second fixation points were still collected near the very center in the visual field (the image center). Fixation changes are clearly revealed in the scan path maps (Figure 4). Thereafter, the subjects' fixation points remained focused on the artificial elements in the temple landscape and the hotel landscape and focused on the image geometric center in the natural landscape for the remainder of the viewing time. The results demonstrate that artificial elements in the natural landscape are more likely to attract subjects' attention.

\subsection{Eye Movement and Value Assessment of Three Landscapes}

One-way repeated measures ANOVA was conducted to test the visual differences between the natural, temple, and hotel landscapes. The results show that the FCs of the three landscapes are different in terms of statistical significance $(\mathrm{F}=7.532, p=0.001)$. The hotel landscape has the highest viewing counts with a mean of 19.858. The FC mean of the temple landscape is 18.792. The natural landscape shows the lowest viewing counts with a mean of 16.962. The hotel and temple landscapes received more information and attention than compared to the natural landscape. The same results were found in FD. For the three landscapes, the hotel landscape shows the highest FD. The FD mean values of the hotel and temple landscapes are $5.033 \mathrm{~s}$ and $4.926 \mathrm{~s}$, respectively, which are also higher than that of the natural landscape, which is $4.267 \mathrm{~s}$. There is also a significant difference statistically in FD among the three landscapes $(\mathrm{F}=4.521, p=0.012)$. This demonstrates that artificial elements in the natural mountain landscape impact visual perception, further proving Hypothesis 1 . The same method was applied to analyze the differences in landscape value assessment. Three landscape types differ significantly in their aesthetic value $(F=18.285$, $p=0.000)$. Likewise, the cultural values of the three landscapes are also different in terms of statistical significance $(F=44.770, p=0.000)$. The temple landscape obtained the highest score both in aesthetic value $($ mean $=3.641)$ and cultural value $($ mean $=3.719)$, while the hotel landscape obtained the lowest score both in aesthetic value (mean $=3.260)$ and cultural value (mean $=2.994)$. Hypothesis 2 was confirmed. The difference is clearly revealed by the boxplots of eye movement and value assessment for the three landscapes (Figure 5).
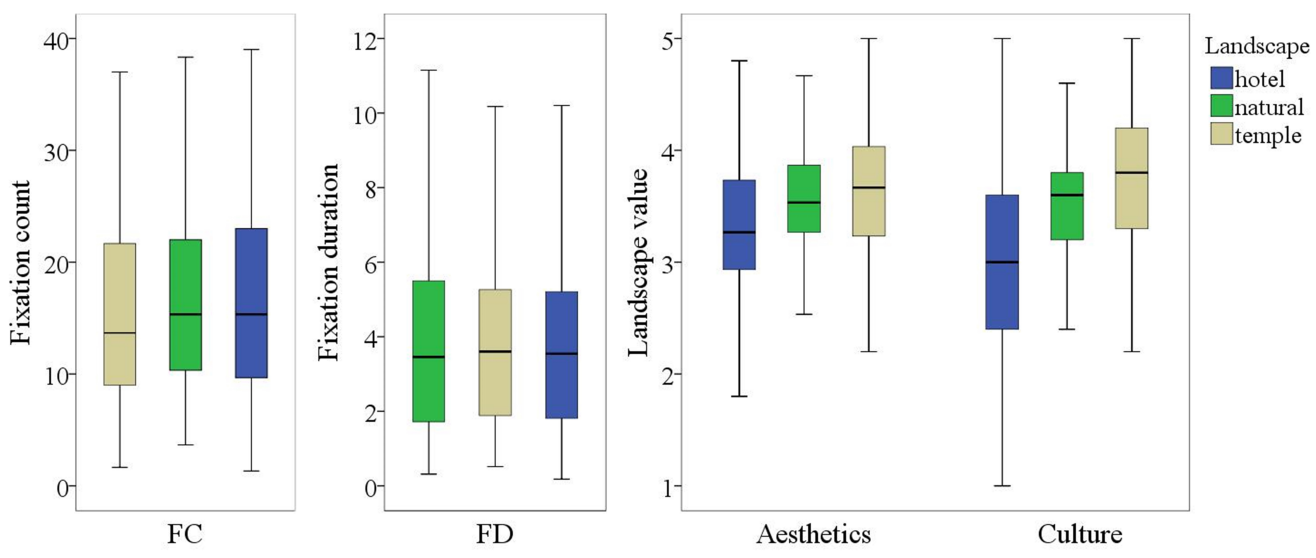

Figure 5. Boxplots of eye movement and value assessment for the three landscapes. The fixation count is measured in counts (c), and the fixation duration is measured in seconds (s).

A least significant difference pairwise comparison method was used to further discuss each difference between the three landscapes; the results are shown in Tables 2 and 3. The results demonstrate that temples and hotels have a significantly higher FC and FD than a purely natural landscape, while there is no significant difference between the temple and hotel landscapes. Natural and temple landscapes differed significantly from the hotel landscape in terms of aesthetic value, while the difference between the natural and temple landscapes was not significant. Compared to the hotel landscape, the natural landscape and temple landscape had higher aesthetic and cultural values. Regarding cultural value, 
each landscape differed significantly from one another. The hotel landscape has far less cultural value than the two other landscapes, and the temple landscape received the highest cultural value assessment score (Table 2). The same conclusions can also be drawn from Figure 5.

Table 2. Statistical description of three landscapes in terms of eye movement and landscape values.

\begin{tabular}{cccccccccc}
\hline \multirow{2}{*}{ Landscape } & \multicolumn{3}{l}{ Fixation Count } & \multicolumn{4}{l}{ Fixation Duration } & \multicolumn{3}{c}{ Aesthetic Value } & \multicolumn{3}{c}{ Cultural Value } & \multirow{2}{*}{ N } \\
\cline { 2 - 9 } & Mean & SD & Mean & SD & Mean & SD & Mean & SD & \\
\hline Natural & 16.962 & 11.372 & 4.267 & 3.171 & 3.580 & 0.490 & 3.465 & 0.578 & 96 \\
Temple & 18.792 & 14.297 & 4.926 & 4.390 & 3.641 & 0.611 & 3.719 & 0.604 & 96 \\
Hotel & 19.858 & 14.420 & 5.033 & 4.502 & 3.260 & 0.735 & 2.994 & 0.942 & 96 \\
\hline
\end{tabular}

Table 3. Least significant difference pairwise comparison of three landscapes.

\begin{tabular}{|c|c|c|c|c|c|c|c|c|c|}
\hline \multirow{2}{*}{ Landscape Pairs } & \multicolumn{2}{|c|}{ Fixation Count } & \multicolumn{2}{|c|}{ Fixation Duration } & \multicolumn{2}{|c|}{ Aesthetic Value } & \multicolumn{2}{|c|}{ Cultural Value } & \multirow{2}{*}{$\mathbf{N}$} \\
\hline & $p$ & SD Er. & $p$ & SD Er. & $p$ & SD Er. & $p$ & SD Er. & \\
\hline Natural-Temple & 0.040 & 0.016 & 0.010 & 0.018 & 0.336 & 0.063 & 0.000 & 0.068 & 96 \\
\hline Natural-Hotel & 0.001 & 0.018 & 0.021 & 0.020 & 0.000 & 0.081 & 0.000 & 0.101 & 96 \\
\hline Temple-Hotel & 0.406 & 0.015 & 0.929 & 0.016 & 0.000 & 0.062 & 0.000 & 0.082 & 96 \\
\hline
\end{tabular}

\subsection{Socio-Demographic Differences in Landscape Perception}

Two variables, landscape type and demographics, were tested by using two-way repeated-measures ANOVA. Tests of the within-subjects effect indicated that the differences of eye movement and value assessment between the three landscapes (natural, temple, and hotel) were significant, consistent with the analysis above. All three demographic features (gender, expertise, and nationality) have no interaction effect on landscape type. This means that whether demographic features show a significant difference in eye movement or landscape value assessment had no significant relevance to the variable of landscape type. We directly obtained the difference between demographic features from the tests of the between-subjects effect (Table 4). Eye movement, i.e., both FC and FD, shows significant differences between men and women. Gender, expertise, and nationality are the demographic reasons for the differences in landscape value assessment.

Table 4. Demographic differences in eye movement and landscape value assessment.

\begin{tabular}{cccccccccc}
\hline \multirow{2}{*}{$\begin{array}{c}\text { Demographic } \\
\text { Feature }\end{array}$} & \multicolumn{2}{c}{ Fixation Count } & \multicolumn{6}{c}{ Fixation Duration } & \multicolumn{2}{c}{ Aesthetic Value } & \multicolumn{2}{c}{ Cultural Value } & \multirow{2}{*}{ N } \\
\cline { 2 - 9 } & $\mathbf{F}$ & $\boldsymbol{p}$ & $\mathbf{F}$ & $\boldsymbol{p}$ & $\mathbf{F}$ & $\boldsymbol{p}$ & $\mathbf{F}$ & $\boldsymbol{p}$ & \\
\hline Gender & 9.682 & 0.002 & 7.743 & 0.007 & 5.075 & 0.027 & 0.170 & 0.681 & F47, M49 \\
Expertise & 0.831 & 0.364 & 0.425 & 0.516 & 3.012 & 0.086 & 4.611 & 0.034 & E36, L60 \\
Nationality & 2.282 & 0.134 & 2.576 & 0.112 & 10.869 & 0.001 & 7.973 & 0.006 & C75, F21 \\
\hline
\end{tabular}

There are significant gender differences in visual perception, with higher FC and FD in males than females. Men tended to observe the landscape images in more detail and for a longer duration. Likewise, men generally showed higher landscape value assessment scores, whereas women showed higher cultural value assessment. Compared to laymen, experts have higher FCs and longer viewing times but lower landscape value assessment scores. Foreigners appeared to score higher than Chinese participants in terms of both eye movement and landscape value assessments. Although eye movement differences in expertise and nationality showed no statistical significance, the obvious gaps were indicated by comparing the mean values of FC and FD between experts and laymen and between Chinese and foreigners. Women scored a higher average cultural value than men in terms of natural landscapes, which may account for the insignificant difference. Figure 6 illustrates the difference in the mean values in gender, expertise, and nationality, which solidly supports our analysis above. Therefore, we claim that demographic features such 
as gender, expertise, and nationality show differences in general. That is, demographic features have impacts on landscape observation and evaluation. The validity of Hypothesis 3 is thereby demonstrated.
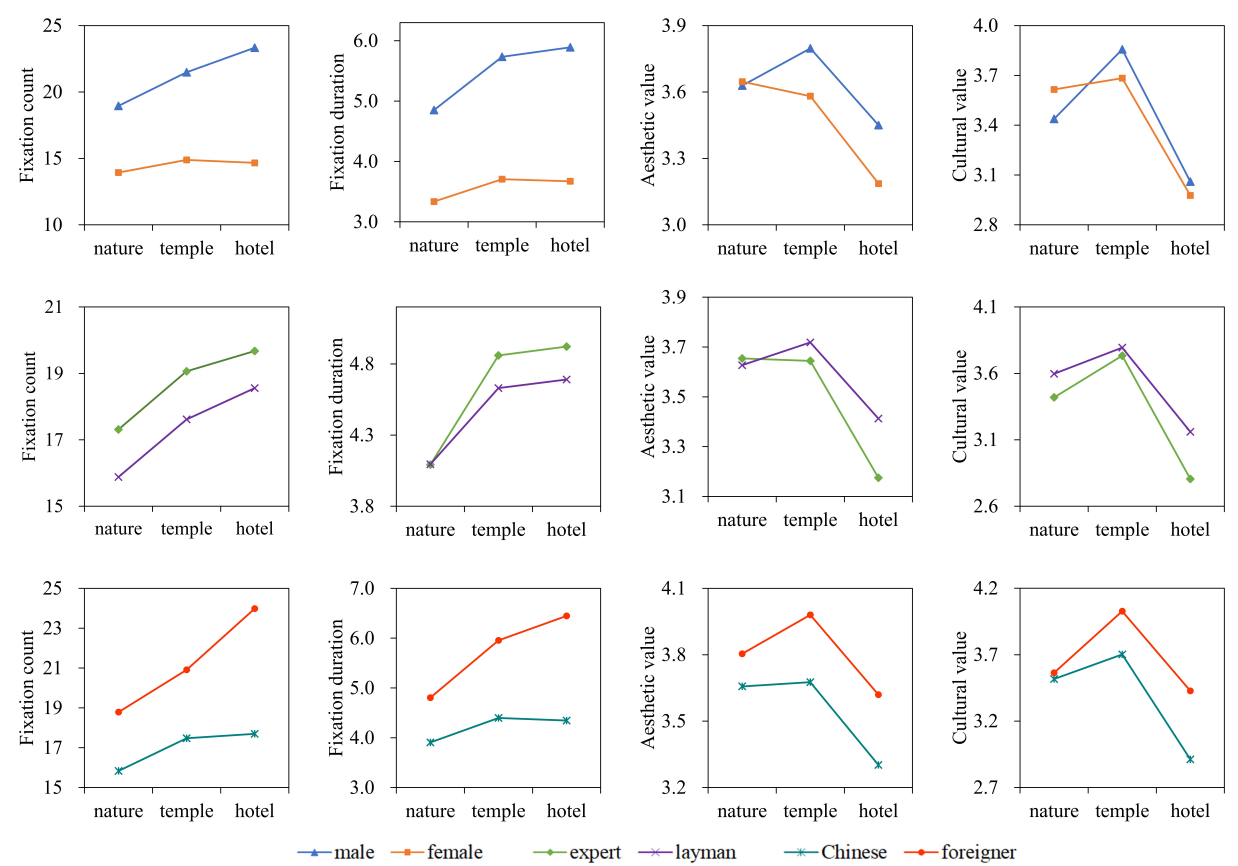

Figure 6. Mean values of eye movement and landscape assessment under gender, expertise, and nationality. The fixation count is measured in counts (c), and the fixation duration is measured in seconds (s).

\section{Discussion}

Landscape perception is an integrated outcome of the intrinsic physical appearance of the landscape and a posteriori knowledge of social demographics $[1,105]$. In the present study, we applied a systematic method to verify this landscape perception process by combining eye movement and value assessment. Both eye movement and value assessment can be regarded as the outcome of human-landscape interactions, both of which can manifest landscape perception. Based on the philosophical ideologies of his time, Lothian (1999) [105] compared the objectivist and subjectivist paradigms in landscape assessment. He concluded that the subjective method is a more reasonable method for evaluating the landscape. In this research, we found that the physical features of a landscape are as important as the eye of the beholder because they are prerequisites for capturing people's attention. Objectivity, in this study, refers to the type of data we obtained that owe less to individual subjectivity; therefore, such methods more realistically reflect the underlying laws of landscape perception. Some studies have been conducted by combining objective and subjective methods to evaluate landscape $[49,106,107]$. Our results indicate that eye tracking might be feasible as an alternative or complementary method in landscape research to enable a more objective and scientific study, which corresponds to the conclusions in other studies in this field $[75,76]$.

Here, we emphasize that artificial elements impact landscape visual perception and value assessment and that gender, expertise, and nationality, because of the different experience and knowledge, also show different perceptual modes and characteristics. Eyetracking has been used in tourism studies mainly on advertisement effectiveness, with few studies on rural or urban landscape research and almost none on tourism landscape research $[87,91,108]$. However, visual characteristics are essential for tourism landscape because tourists first visually receive sensory information of the surrounding environment. Our observations contribute to a better understanding of landscape perception and the 
impact of artificial elements on landscape theoretically by combining visual behavior with value assessment, providing, therefore, proper and practical guidance for landscape utilization and tourism planning.

\subsection{The Impact of Artificial Elements on Mountain Landscape Perception}

The landscape has played a crucial role in attracting tourists. As pointed out in the existing literature, aesthetics and culture are two of the most palpable features of the landscape embedded in a particular place $[9,11,14,15,22-26,93,94]$. Our research results further confirmed this: the temple landscape received the highest assessment score both in aesthetic and cultural value, and the natural landscape received a higher aesthetic value score because of their ecological traits and restorative and recreational benefits $[4,109]$.

Harmony has long been used as a major criterion in landscape value assessment [36-42]. Existing research has shown that a landscape without artificial elements is perceived as harmonious [42]. However, our study shows that special artificial structures may be equally coherent with their natural surroundings. This is indicated by the temple landscape, which tends to have a more traditional structure, scoring higher on harmony than the natural landscape, which is consistent with the results of existing research $[31,50,93]$. Temples, especially Taoist temples, are places where people seek peace, relaxation, and spiritual solace, and such temples are built explicitly by integrating human and natural elements. The features of such places are appealing to stressed people living in modern cities with busy lives $[32,68,110]$. Traditional elements such as temples have long been perceived as coexisting with mountain landscapes or being rooted in the mountains for thousands of years. Thus, people may tend to perceive temples as harmonious with its mountainous surroundings. On the contrary, modern hotels appeared relatively recently with industrialization and globalization. People might have a more traditional perspective and may not be used to such modern objects visually and cognitively [111,112], and such man-made structures may be considered disharmonious or intrusive elements.

Existing research shows that artificial elements are given more visual sensitivity in a landscape. The more visually sensitive the landscape is, the more visual pollution will be caused, and the more disharmonious the landscape will be $[45,48,85,113]$. This is reflected in this study. Hotels are the most obtrusive element and are perceived first and foremost. Temples received more attention from the subjects than their natural surroundings. Although temple landscapes received the highest assessment value (both in aesthetics and culture), they received less viewing time and attention than hotels. Similarly, hotel landscapes had the lowest value but received the most visual attention; natural landscapes had a moderate value and received the least visual attention. Therefore, landscape surface features and people's interests could be implied by the visual attention to some extent, but not all aspects. In this study, the subjects' landscape value assessment only partially reflected their visual characteristics. The mechanism between visual behavior and value assessment during landscape perception requires further investigation.

\subsection{Demographic Differences in Mountain Landscape Perception}

As research has shown a preference for the empiricism paradigm recently, knowledge acquired from experience in a particular circumstance (a posteriori knowledge) is recognized as an essential factor affecting landscape perception. Gender, expertise, and nationality are three of the variables most often studied [59-63]. In this study, men showed higher value assessment scores and paid more visual attention to landscapes than women, with the exception of natural landscapes. Men had lower value assessment scores for the natural landscape and higher value assessment scores for the temple and hotel landscapes. This significant gender difference is consistent with the studies of Li et al. [82] and Wang et al. [84] which have shown that men are more likely to perceive the humanistic attribute than compared to women. As revealed by many studies, gender also significantly affects attribute recognition of tourism destinations, value assessment, and travel behavior [64,114]. Personality differences between men and women may emerge as the cause of the land- 
scape perception differences. Moreover, the reason people stay in an area with a particular landscape or environment also affected landscape assessment [65,115].

One exciting finding in this study is that the three types of landscapes were paid a greater amount of visual attention but were given lower value assessment scores by experts than laymen. One possible explanation is that experts tend to spend more time scrutinizing the landscape and carry out a stricter standard for value assessment from a professional perspective [66,116]. Furthermore, location also plays an important role in landscape perception. This research shows that people from different countries may hold various opinions about a landscape, consistent with previous studies $[68,98,117]$. In the study presented by Wang et al. (2016) [68], Australian participants fixated more frequently and for longer durations on tourism images than Chinese participants. Fixation also varied with image conditions, with the Chinese group having particularly low fixation durations and counts for the low arousal or natural condition. Perhaps because of their curiosity or yearning for novelty, foreigners might have longer visual attention span and provide higher value assessment scores of the landscapes than native subjects.

\subsection{Limitations and Future Research}

This paper has certain limitations. First, using landscape images may have been resulted in conclusions that are similar to those made using actual landscapes; however, the limited number of images and photographic techniques cannot completely replace an actual landscape. Additionally, landscape information may be omitted from the images. Panoramic photos or virtual reality might be a better alternative in obtaining research results accurately $[104,118]$. Second, this study included only college students as subjects. In future research, a more diversified sample, with different educational backgrounds and age groups, is needed in order to improve the validity of the research. The number of participants is a key factor for validity and efficacy in a study. Although a sample containing over 30 participants has been reported as a valid sample size in previous eye movement studies $[68,87,104]$, social surveys such as the landscape assessment used in this study generally required a larger sample size, around 300-500 participants [16]. It is essential to connect psychological experiments and social surveys properly to discover the underlying implications. Eye-tracking still remains a new tool in landscape research, and it might be more appropriate to use it as an assisted method functioning together with questionnaires. Finally, human visual perception and psychological cognition are two mutually influenced processes; the interaction between subjects' visual attention to landscapes and their real interest in it requires further discussion. Visual fixations are selected according to visual acuity and color sensitivity in a human vision system. The visual-cognitive system patterns the viewing process by actively controlling fixations directly relative to important and informative visual cues [119]. In addition, layout, colors, lighting, and other attributes of landscape photos require thorough consideration in future research.

\section{Conclusions}

This study aimed to examine the effect of artificial elements on mountain landscape perception through the eye-tracking method. Our results indicate that artificial elements stand out visually in a natural landscape. The hotel, a modern artificial entity, is considered as visual pollution and received negative landscape value assessments. By contrast, the temple is generally regarded as a traditional and distinctive element that is harmonious with the mountain landscape. Temples have a higher landscape value because of their spiritual significance, which demonstrates that temples should be preserved as valuable tourism resources. Modern artificial facilities such as hotels are considered to have a greater visual impact and should be evaluated before construction. Otherwise, improper construction in a landscape may become a negative intrusion, similarly to a misplaced brushstroke in a painting, resulting in abandoned tourism sites and a waste of tourism resources. More attention should be paid to the negative impact of modern buildings in 
already harmonious environments, and more sustainable tourism development in such areas is needed. For mountainous tourism areas, hotels could be located at the foot of or around mountains instead of at the mountainsides or peaks. Architectural design with more harmonious appearance (i.e., in terms of color, shape, materials, etc.) with relative to the surrounding natural landscape should be given more attention in tourism planning and development. For the most famous mountain tourism spots, such as Mount Huang, a two-day trip with a one night stay on a mountain is necessary, causing the demand for accommodation. The academic and practical question of how tourist demand can be balanced with landscape protection remains to be investigated for tourism planners and developers, and more research is needed in the future.

Based on the theories of environmental psychology, this study tested whether sociodemographic factors affect landscape perception in a top-down cognitive mode. The findings indicate that gender, expertise, and nationality affect both landscape visual behaviors and landscape value assessments. Men, in general, observed the landscapes in more detail and for a longer duration; men also had higher landscape value assessment scores than women. Experts were more likely to observe landscapes with greater scrutiny and provide lower landscape value assessment scores, probably due to their professional knowledge on landscapes. In terms of both eye movement and landscape value assessment, foreigners scored higher than Chinese participants. Curiosity is probably the most relevant explanation for this difference.

This study measured landscape visual perception and value assessments by an eyetracking experiment on artificial elements interfering with mountain landscapes. A systematic research framework combining the external factors of landscape surface features and internal factors of socio-demographics was applied. Eye-tracking as a method recently applied in landscape research can obtain a more objective and quantitative visual behavior data. The feasibility of the eye-tracking method on landscape perception research has been tested in this study, which provides certain theoretical and methodological innovations. Nevertheless, as a primary study, there are still some limitations. The images used were mainly second-hand images. Photographs taken by the researchers themselves might contain more landscape information. Furthermore, panoramic images or virtual reality technologies might reveal more information if applied to landscape research. Additionally, sample selection must be considered more rigorously. The relationship between eye movement and landscape assessment and the underlying mechanism require further discussions.

Author Contributions: Conceptualization, S.G.; methodology, S.G.; software, S.G.; validation, S.G. and P.L.; formal analysis, S.G.; investigation, S.G.; resources, S.G. and J.Z.; data curation, S.G.; writing —original draft preparation, S.G.; writing—review and editing, S.G., W.S., W.C., J.Z. and P.L.; visualization, S.G.; supervision, W.C. and J.Z. All authors have read and agreed to the published version of the manuscript.

Funding: This research was funded by the Strategic Priority Research Program(A) of the Chinese Academy of Sciences, grant number XDA230201, and the Key R\&D Program of Jiangsu Province, grant number BE2019773. The Strategic Priority Research Program(A) of the Chinese Academy is funded by the Chinese Academy of Sciences, and the Key R\&D Program of Jiangsu Province is funded by the Jiangsu Provincial Department of Science and Technology.

Institutional Review Board Statement: Not applicable.

Informed Consent Statement: Not applicable.

Data Availability Statement: Not applicable.

Conflicts of Interest: The authors declare no conflict of interest. 


\section{References}

1. Zube, E.H.; Sell, J.L.; Taylor, J.G. Landscape perception: Research, application and theory. Landsc. Plan. 1982, 9, 1-33. [CrossRef]

2. Cosgrove, D.; Daniels, S. The Iconography of Landscape: Essays on the Symbolic Representation, Design and Use of Past Environments; Cambridge University Press: Cambridge, UK, 1988; Volume 9.

3. Cosgrove, D.E. Social Formation and Symbolic Landscape; Univ. of Wisconsin Press: Madison, WI, USA, 1998.

4. Kaplan, R.; Kaplan, S. The Experience of Nature: A Psychological Perspective; Cambridge University Press: Cambridge, UK, 1989.

5. Qiu, H.; Hsu, C.; Li, M.; Shu, B. Self-drive tourism attributes: Influences on satisfaction and behavioural intention. Asia Pac. J. Tour. Res. 2018, 23, 395-407. [CrossRef]

6. Tyrväinen, L.; Silvennoinen, H.; Nousiainen, I.; Tahvanainen, L. Rural tourismin Finland: Tourists' expectation of landscape and environment. Scand. J. Hosp. Tour. 2001, 1, 133-149. [CrossRef]

7. Gibson, J.J. The Perception of the Visual World; Houghton Mifflin: Boston, MA, USA, 1950.

8. Anderson, J.R.; Boyle, C.F.; Corbett, A.T.; Lewis, M.W. Cognitive modeling and intelligent tutoring. Artif. Intell. 1990, 42, 7-49. [CrossRef]

9. Di, F.; Yang, Z.; Liu, X.; Wu, J.; Ma, Z. Estimation on aesthetic value of tourist landscapes in a natural heritage site: Kanas National Nature Reserve, Xinjiang, China. Chin. Geogr. Sci. 2010, 20, 59-65. [CrossRef]

10. Menatti, L.; Casado da Rocha, A. Landscape and health: Connecting psychology, aesthetics, and philosophy through the concept of affordance. Front. Psychol. 2016, 7, 571. [CrossRef]

11. Ribe, R.G. A general model for understanding the perception of scenic beauty in northern hardwood forests. Landsc. J. 1990, 9, 86-101. [CrossRef]

12. Stern, R.M.; Ray, W.J.; Quigley, K.S. Psychophysiological Recording; Oxford University Press: Oxford, UK, 2001.

13. Daniel, T.C.; Boster, R.S. Measuring Landscape Esthetics: The Scenic Beauty Estimation Method; USDA Forest Service, Rocky Mountain Forest and Range Experiment Station: Fort Collins, CO, USA, 1976; Volume 167.

14. Gobster, P.H.; Nassauer, J.I.; Daniel, T.C.; Fry, G. The shared landscape: What does aesthetics have to do with ecology? Landsc. Ecol. 2007, 22, 959-972. [CrossRef]

15. Rosley, M.S.F.; Lamit, H.; Rafida, S. Aesthetic and Perception: Indicators of perceiving the rural landscape. Asian J. Behav. Stud. 2017, 2, 11-22. [CrossRef]

16. Tveit, M.S.; Ode Sang, Å.; Hagerhall, C.M. Scenic beauty: Visual landscape assessment and human landscape perception. Environ. Psychol. Introd. 2018, 2018, 45-54.

17. Osgood, C.E. Semantic differential technique in the comparative study of cultures 1. Am. Anthropol. 1964, 66, 171-200. [CrossRef]

18. Arriaza, M.; Cañas-Ortega, J.F.; Cañas-Madueño, J.A.; Ruiz-Aviles, P. Assessing the visual quality of rural landscapes. Landsc. Urban Plan. 2004, 69, 115-125. [CrossRef]

19. Bulut, Z.; Yilmaz, H. Determination of landscape beauties through visual quality assessment method: A case study for Kemaliye (Erzincan/Turkey). Environ. Monit. Assess. 2008, 141, 121-129. [CrossRef] [PubMed]

20. Chen, B.; Adimo, O.A.; Bao, Z. Assessment of aesthetic quality and multiple functions of urban green space from the users' perspective: The case of Hangzhou Flower Garden, China. Landsc. Urban Plan. 2009, 93, 76-82. [CrossRef]

21. Ramírez, Á.; Ayuga-Téllez, E.; Gallego, E.; Fuentes, J.M.; García, A.I. A simplified model to assess landscape quality from rural roads in Spain. Agric. Ecosyst. Environ. 2011, 142, 205-212. [CrossRef]

22. Knudsen, D.C.; Soper, A.K.; Metro-Roland, M. Commentary: Gazing, performing and reading: A landscape approach to understanding meaning in tourism theory. Tour. Geogr. 2007, 9, 227-233. [CrossRef]

23. Metro-Roland, M. Interpreting meaning: An application of Peircean semiotics to tourism. Tour. Geogr. 2009, 11, 270-279. [CrossRef]

24. Davenport, M.A.; Anderson, D.H. Getting from sense of place to place-based management: An interpretive investigation of place meanings and perceptions of landscape change. Soc. Nat. Resour. 2005, 18, 625-641. [CrossRef]

25. Quinn, T.; Bousquet, F.; Guerbois, C.; Sougrati, E.; Tabutaud, M. The dynamic relationship between sense of place and risk perception in landscapes of mobility. Ecol. Soc. 2018, 23. [CrossRef]

26. Tuan, Y.F. Space and Place: The Perspective of Experience; U of Minnesota Press: Minneapolis, MN, USA, 1977.

27. Taylor, K. The Historic Urban Landscape paradigm and cities as cultural landscapes. Challenging orthodoxy in urban conservation. Landsc. Res. 2016, 41, 471-480. [CrossRef]

28. Tieskens, K.F.; Schulp, C.J.; Levers, C.; Lieskovskỳ, J.; Kuemmerle, T.; Plieninger, T.; Verburg, P.H. Characterizing European cultural landscapes: Accounting for structure, management intensity and value of agricultural and forest landscapes. Land Use Policy 2017, 62, 29-39. [CrossRef]

29. Tilley, C. Introduction: Identity, place, landscape and heritage. J. Mater. Cult. 2006, 11, 7-32. [CrossRef]

30. Wynveen, C.J.; Kyle, G.T.; Sutton, S.G. Natural area visitors' place meaning and place attachment ascribed to a marine setting. J. Environ. Psychol. 2012, 32, 287-296. [CrossRef]

31. Cartier, C. Megadevelopment in Malaysia: From heritage landscapes to “leisurescapes" in Melaka's tourism sector. Singap. J. Trop. Geogr. 1998, 19, 151-176. [CrossRef]

32. Jiang, T.; Ryan, C.; Zhang, C. The spiritual or secular tourist? The experience of Zen meditation in Chinese temples. Tour. Manag. 2018, 65, 187-199. [CrossRef] 
33. Chmielewski, S.; Lee, D.J.; Tompalski, P.; Chmielewski, T.J.; Wężyk, P. Measuring visual pollution by outdoor advertisements in an urban street using intervisibilty analysis and public surveys. Int. J. Geogr. Inf. Sci. 2016, 30, 801-818. [CrossRef]

34. Jana, M.K.; De, T. Visual pollution can have a deep degrading effect on urban and suburban community: A study in few places of Bengal, India, with special reference to unorganized billboards. Eur. Sci. J. 2015, 11, 1-14.

35. Ode, Å.; Tveit, M.S.; Fry, G. Capturing landscape visual character using indicators: Touching base with landscape aesthetic theory. Landsc. Res. 2008, 33, 89-117. [CrossRef]

36. Gahwiler, P.; Havitz, M.E. Toward a relational understanding of leisure social worlds, involvement, psychological commitment, and behavioral loyalty. Leis. Sci. 1998, 20, 1-23. [CrossRef]

37. Nohl, W. Sustainable landscape use and aesthetic perception-preliminary reflections on future landscape aesthetics. Landsc. Urban Plan. 2001, 54, 223-237. [CrossRef]

38. Palmer, J.F. The perceived scenic effects of clearcutting in the White Mountains of New Hampshire, USA. J. Environ. Manag. 2008, 89, 167-183. [CrossRef] [PubMed]

39. Rössler, M. World heritage cultural landscapes: A UNESCO flagship programme 1992-2006. Landsc. Res. 2006, 31, 333-353. [CrossRef]

40. Tveit, M.; Ode, Å.; Fry, G. Key concepts in a framework for analysing visual landscape character. Landsc. Res. 2006, 31, 229-255. [CrossRef]

41. Zukin, S. Reconstructing the authenticity of place. Theory Soc. 2011, 40, 161-165. [CrossRef]

42. Sowifska-fwierkosz, B. Index of Landscape Disharmony (ILDH) as a new tool combining the aesthetic and ecological approach to landscape assessment. Ecol. Indic. 2016, 70, 166-180. [CrossRef]

43. Canter, L.W.; Hill, L.G. Handbook of Variables for Environmental Impact Assessment; Ann Arbor Science Publishers: Ann Arbor, MI, USA, 1979.

44. Shang, H.; Bishop, I.D. Visual thresholds for detection, recognition and visual impact in landscape settings. J. Environ. Psychol. 2000, 20, 125-140. [CrossRef]

45. Palmer, J.F. The contribution of a GIS-based landscape assessment model to a scientifically rigorous approach to visual impact assessment. Landsc. Urban Plan. 2019, 189, 80-90. [CrossRef]

46. Garré, S.; Meeus, S.; Gulinck, H. The dual role of roads in the visual landscape: A case-study in the area around Mechelen (Belgium). Landsc. Urban Plan. 2009, 92, 125-135. [CrossRef]

47. Rodrigues, M.; Montañés, C.; Fueyo, N. A method for the assessment of the visual impact caused by the large-scale deployment of renewable-energy facilities. Environ. Impact Assess. Rev. 2010, 30, 240-246. [CrossRef]

48. Sklenicka, P.; Zouhar, J. Predicting the visual impact of onshore wind farms via landscape indices: A method for objectivizing planning and decision processes. Appl. Energy 2018, 209, 445-454. [CrossRef]

49. del Carmen Torres-Sibille, A.; Cloquell-Ballester, V.A.; Cloquell-Ballester, V.A.; Ramírez, M.Á.A. Aesthetic impact assessment of solar power plants: An objective and a subjective approach. Renew. Sustain. Energy Rev. 2009, 13, 986-999. [CrossRef]

50. Fatimah, T. The impacts of rural tourism initiatives on cultural landscape sustainability in Borobudur area. Procedia Environ. Sci. 2015, 28, 567-577. [CrossRef]

51. Korça, P. Resident perceptions of tourism in a resort town. Leis. Sci. 1998, 20, 193-212. [CrossRef]

52. Noll, D.; Wiedenhofer, D.; Miatto, A.; Singh, S.J. The expansion of the built environment, waste generation and EU recycling targets on Samothraki, Greece: An island's dilemma. Resour. Conserv. Recycl. 2019, 150, 104405. [CrossRef]

53. Puczko, L.; Ratz, T. Tourist and resident perceptions of the physical impacts of tourism at Lake Balaton, Hungary: Issues for sustainable tourism management. J. Sustain. Tour. 2000, 8, 458-478. [CrossRef]

54. Corbetta, M.; Shulman, G.L. Control of goal-directed and stimulus-driven attention in the brain. Nat. Rev. Neurosci. 2002, 3, 201-215. [CrossRef]

55. Delorme, A.; Rousselet, G.A.; Macé, M.J.M.; Fabre-Thorpe, M. Interaction of top-down and bottom-up processing in the fast visual analysis of natural scenes. Cogn. Brain Res. 2004, 19, 103-113. [CrossRef]

56. Gerrig, R.J.; Zimbardo, P.G. Psychology and Life; Pearson Education: Boston, MA, USA, 2009.

57. Burns, T.R.; Engdahl, E. The social construction of consciousness. Part 1: Collective consciousness and its socio-cultural foundations. J. Conscious. Stud. 1998, 5, 67-85.

58. Vespestad, M.K.; Lindberg, F. Understanding nature-based tourist experiences: An ontological analysis. Curr. Issues Tour. 2011, 14, 563-580. [CrossRef]

59. Bruwer, J.; Joy, A. Tourism destination image (TDI) perception of a Canadian regional winescape: A free-text macro approach. Tour. Recreat. Res. 2017, 42, 367-379. [CrossRef]

60. Buijs, A.E.; Pedroli, B.; Luginbühl, Y. From hiking through farmland to farming in a leisure landscape: changing social perceptions of the European landscape. Landsc. Ecol. 2006, 21, 375-389. [CrossRef]

61. Gkargkavouzi, A.; Halkos, G.; Matsiori, S. Environmental behavior in a private-sphere context: Integrating theories of planned behavior and value belief norm, self-identity and habit. Resour. Conserv. Recycl. 2019, 148, 145-156. [CrossRef]

62. Wang, R.; Zhao, J. Demographic groups' differences in visual preference for vegetated landscapes in urban green space. Sustain. Cities Soc. 2017, 28, 350-357. [CrossRef]

63. Yoo, C.K.; Yoon, D.; Park, E. Tourist motivation: An integral approach to destination choices. Tour. Rev. 2018. [CrossRef] 
64. Meng, F.; Uysal, M. Effects of gender differences on perceptions of destination attributes, motivations, and travel values: An examination of a nature-based resort destination. J. Sustain. Tour. 2008, 16, 445-466. [CrossRef]

65. Perera, D.; Chandrasekara, D. Influence of Gender on Perception of Landscape: A Study of Viharamahadevi Park in Colombo. Proc. Int. For. Environ. Symp. 2017, 22. [CrossRef]

66. Dupont, L.; Antrop, M.; Van Eetvelde, V. Does landscape related expertise influence the visual perception of landscape photographs? Implications for participatory landscape planning and management. Landsc. Urban Plan. 2015, 141, 68-77. [CrossRef]

67. Potschin, M.; Haines-Young, R. Landscapes, sustainability and the place-based analysis of ecosystem services. Landsc. Ecol. 2013, 28, 1053-1065. [CrossRef]

68. Wang, Y.; Sparks, B.A. An eye-tracking study of tourism photo stimuli: Image characteristics and ethnicity. J. Travel Res. 2016, 55, 588-602. [CrossRef]

69. Daniel, T.C. Whither scenic beauty? Visual landscape quality assessment in the 21st century. Landsc. Urban Plan. 2001, 54, 267-281. [CrossRef]

70. Peterson, G.L.; Neumann, E.S. Modeling and predicting human response to the visual recreation environment. J. Leis. Res. 1969, 1, 219-237. [CrossRef]

71. Shafer Jr, E.L.; Brush, R.O. How to measure preferences for photographs of natural landscapes. Landsc. Plan. 1977, 4, 237-256. [CrossRef]

72. Zhao, J.; Yan, Y.; Deng, H.; Liu, G.; Dai, L.; Tang, L.; Shi, L.; Shao, G. Remarks about landsenses ecology and ecosystem services. Int. J. Sustain. Dev. World Ecol. 2020, 27, 196-201. [CrossRef]

73. Li, J.; Zhang, Z.; Jing, F.; Gao, J.; Ma, J.; Shao, G.; Noel, S. An evaluation of urban green space in Shanghai, China, using eye tracking. Urban For. Urban Green. 2020, 56, 126903. [CrossRef]

74. De Lucio, J.; Mohamadian, M.; Ruiz, J.; Banayas, J.; Bernaldez, F. Visual landscape exploration as revealed by eye movement tracking. Landsc. Urban Plan. 1996, 34, 135-142. [CrossRef]

75. Guo, S.; Zhao, N.; Zhang, J.; Xue, T.; Liu, P.; Xu, S.; Xu, D. Landscape visual quality assessment based on eye movement: College student eye-tracking experiments on tourism landscape pictures. Resour. Sci. 2017, 39, 1137-1147.

76. Sun, L.; Shao, H.; Li, S.; Huang, X.; Yang, W. Integrated application of eye movement analysis and beauty estimation in the visual landscape quality estimation of urban waterfront park. Int. J. Pattern Recognit. Artif. Intell. 2018, 32, 1856010. [CrossRef]

77. Duchowski, A.T. A breadth-first survey of eye-tracking applications. Behav. Res. Methods Instrum. Comput. 2002, 34, 455-470. [CrossRef]

78. Haber, R.N.; Hershenson, M. The Psychology of Visual Perception; Holt, Rinehart \& Winston: New York, NY, USA, 1973.

79. Liu, Y.; Hu, M.; Zhao, B. Interactions between forest landscape elements and eye movement behavior under audio-visual integrated conditions. J. For. Res. 2020, 25, 21-30. [CrossRef]

80. Nordh, H.; Hagerhall, C.M.; Holmqvist, K. Tracking restorative components: Patterns in eye movements as a consequence of a restorative rating task. Landsc. Res. 2013, 38, 101-116. [CrossRef]

81. Amati, M.; Parmehr, E.G.; McCarthy, C.; Sita, J. How eye-catching are natural features when walking through a park? Eye-tracking responses to videos of walks. Urban For. Urban Green. 2018, 31, 67-78. [CrossRef]

82. Li, X.Q.; Zhao, N.X.; Wang, C.Z.; Wang, M.; Huang, H. A preliminary study on the application of eye tracker to the landmark landscape of campus tourism-Taking the north building of Nanjing University as an example. Acta Agric. Jiangxi 2011, 23, 148-151.

83. Ren, X.; Kang, J. Interactions between landscape elements and tranquility evaluation based on eye tracking experiments. J. Acoust. Soc. Am. 2015, 138, 3019-3022. [CrossRef]

84. Wang, P.; Yang, W.; Wang, D.; He, Y. Insights into Public Visual Behaviors through Eye-Tracking Tests: A Study Based on National Park System Pilot Area Landscapes. Land 2021, 10, 497. [CrossRef]

85. Misthos, L.M.; Pavlidis, A.; Karabassakis, E.; Menegaki, M.; Krassanakis, V.; Nakos, B. Exploring the visual impact from open pit mines applying eye movement analyses on mining landscape photographs. Int. J. Min. Reclam. Environ. 2020, 34, 609-624. [CrossRef]

86. Scott, N.; Green, C.; Fairley, S. Investigation of the use of eye tracking to examine tourism advertising effectiveness. Curr. Issues Tour. 2016, 19, 634-642. [CrossRef]

87. Li, Q.; Huang, Z.J.; Christianson, K. Visual attention toward tourism photographs with text: An eye-tracking study. Tour. Manag. 2016, 54, 243-258. [CrossRef]

88. Wang, J.Y.; Lin, L.; Gao, H.; Feng, Z.L. Differences in college students'spatial symbol cognition of tourism map: Based on experimental data from an eye-movement tracking system. Tour. Trib. 2016, 31, 97-105.

89. Huang, X.; Li, M.; Yan, S. Research on pattern of eye-tracking behavior based on tourism map. Tour. Trib. 2018, 33, 87-96.

90. Dong, W.; Liao, H.; Zhan, Z.; Liu, B.; Wang, S.; Yang, T. New research progress of eye tracking-based map cognition in cartography since 2008. J. Geogr. Sci. 2019, 74, 599-614.

91. Scott, N.; Zhang, R.; Le, D.; Moyle, B. A review of eye-tracking research in tourism. Curr. Issues Tour. 2019, $22,1244-1261$. [CrossRef]

92. Scott, N.; Le, D.; Becken, S.; Connolly, R.M. Measuring perceived beauty of the Great Barrier Reef using eye-tracking technology. Curr. Issues Tour. 2020, 23, 2492-2502. [CrossRef] 
93. Li, F.M.S. Culture as a major determinant in tourism development of China. Curr. Issues Tour. 2008, 11, $492-513$.

94. Li, M.; Wu, B.; Cai, L. Tourism development of World Heritage Sites in China: A geographic perspective. Tour. Manag. 2008, 29, 308-319. [CrossRef]

95. Shepherd, R.J. Faith in Heritage: Displacement, Development, and Religious Tourism in Contemporary China; Left Coast Press: Walnut Creek, CA, USA, 2013

96. UNESCO. World Heritage List: Mount Taishan. 1987. Available online: https://whc.unesco.org/en/list/437 (accessed on 25 August 2021).

97. Sofield, T.; Li, F.M.S. China: Ecotourism and cultural tourism, harmony or dissonance. In Critical Issues in Ecotourism: Understanding a Complex Tourism Phenomenon; Elsevier, Butterworth Heinemann: Amsterdam, NL, USA, 2007 ; pp. 368-385.

98. Beza, B.B. The aesthetic value of a mountain landscape: A study of the Mt. Everest Trek. Landsc. Urban Plan. 2010, 97, 306-317. [CrossRef]

99. Steen Jacobsen, J.K. Use of landscape perception methods in tourism studies: A review of photo-based research approaches. Tour. Geogr. 2007, 9, 234-253. [CrossRef]

100. Kaplan, S. The restorative benefits of nature: Toward an integrative framework. J. Environ. Psychol. 1995, 15, 169-182. [CrossRef]

101. Kaplan, S. Aesthetics, affect, and cognition: Environmental preference from an evolutionary perspective. Environ. Behav. 1987, 19, 3-32. [CrossRef]

102. Fry, G.; Tveit, M.S.; Ode, Å.; Velarde, M. The ecology of visual landscapes: Exploring the conceptual common ground of visual and ecological landscape indicators. Ecol. Indic. 2009, 9, 933-947. [CrossRef]

103. UNESCO; WHC. Operational Guidelines for the Implementation of the World Heritage Convention, Released on 10 July 2019. Available online: https:/ /whc.unesco.org/en/guidelines/ (accessed on 25 August 2021).

104. Dupont, L.; Antrop, M.; Van Eetvelde, V. Eye-tracking analysis in landscape perception research: Influence of photograph properties and landscape characteristics. Landsc. Res. 2014, 39, 417-432. [CrossRef]

105. Lothian, A. Landscape and the philosophy of aesthetics: Is landscape quality inherent in the landscape or in the eye of the beholder? Landsc. Urban Plan. 1999, 44, 177-198. [CrossRef]

106. Aretano, R.; Petrosillo, I.; Zaccarelli, N.; Semeraro, T.; Zurlini, G. People perception of landscape change effects on ecosystem services in small Mediterranean islands: A combination of subjective and objective assessments. Landsc. Urban Plan. 2013, 112, 63-73. [CrossRef]

107. Atik, M.; Işıklı, R.C.; Ortaçeşme, V.; Yıldırım, E. Exploring a combination of objective and subjective assessment in landscape classification: Side case from Turkey. Appl. Geogr. 2017, 83, 130-140. [CrossRef]

108. Hernández-Méndez, J.; Muñoz-Leiva, F. What type of online advertising is most effective for eTourism 2.0? An eye tracking study based on the characteristics of tourists. Comput. Hum. Behav. 2015, 50, 618-625. [CrossRef]

109. Tengberg, A.; Fredholm, S.; Eliasson, I.; Knez, I.; Saltzman, K.; Wetterberg, O. Cultural ecosystem services provided by landscapes: Assessment of heritage values and identity. Ecosyst. Serv. 2012, 2, 14-26. [CrossRef]

110. Ashton, A.S. Spiritual retreat tourism development in the Asia Pacific region: Investigating the impact of tourist satisfaction and intention to revisit: A Chiang Mai, Thailand case study. Asia Pac. J. Tour. Res. 2018, 23, 1098-1114. [CrossRef]

111. Long, H.; Woods, M. Rural restructuring under globalization in eastern coastal China: What can be learned from Wales? J. Rural. Community Dev. 2011, 6, 70-94.

112. Sturken, M.; Cartwright, L. Practices of Looking: An Introduction to Visual Culture; Oxford University Press: New York, NY, USA, 2009.

113. Cloquell-Ballester, V.A.; del Carmen Torres-Sibille, A.; Cloquell-Ballester, V.A.; Santamarina-Siurana, M.C. Human alteration of the rural landscape: Variations in visual perception. Environ. Impact Assess. Rev. 2012, 32, 50-60. [CrossRef]

114. Geng, J.; Long, R.; Chen, H.; Li, W. Exploring the motivation-behavior gap in urban residents' green travel behavior: A theoretical and empirical study. Resour. Conserv. Recycl. 2017, 125, 282-292. [CrossRef]

115. Feingold, A. Gender differences in personality: A meta-analysis. Psychol. Bull. 1994, 116, 429. [CrossRef]

116. Conrad, E.; Fazey, I.; Christie, M.; Galdies, C. Choosing landscapes for protection: Comparing expert and public views in Gozo, Malta. Landsc. Urban Plan. 2019, 191, 103621. [CrossRef]

117. Zhang, C.; Gursoy, D.; Deng, Z.; Gao, J. Impact of culture on perceptions of landscape names. Tour. Geogr. 2015, 17, 134-150. [CrossRef]

118. Portman, M.E.; Natapov, A.; Fisher-Gewirtzman, D. To go where no man has gone before: Virtual reality in architecture, landscape architecture and environmental planning. Comput. Environ. Urban Syst. 2015, 54, 376-384. [CrossRef]

119. Henderson, J.M. Human gaze control during real-world scene perception. Trends Cogn. Sci. 2003, 7, 498-504. [CrossRef] [PubMed] 